\title{
GANBATTE CIMSA UNS sebagai Upaya Edukasi terkait Obesitas pada Masyarakat Daerah Gulon
}

\author{
Frisca Fadhilah Octaviany (G0018085) \\ Prodi Kedokteran, Fakultas Kedokteran, \\ Universitas Sebelas Maret, Surakarta, Indonesia \\ friscafadhilah@student.uns.ac.id
}

\begin{abstract}
Obesity is a serious problem that must be considered in this developing country, especially Indonesia. Based on data from the World Health Organization (WHO) in the last decade, there has been a significant increase in obesity sufferers. Especially women. In Indonesia itself, there has been an increase in obesity sufferers in the last 20 years. This is due to the growing development of technology that makes it easier for humans in all things and an increasingly unhealthy lifestyle. Education to the public regarding obesity is very important. Optimal and routine education is needed so that the surrounding community will be more aware of the dangers of obesity itself. Obesity occurs because of a person's life journey, not just one time. Lack of awareness regarding the complications of obesity itself has led people to underestimate the signs of obesity.
\end{abstract}

Keywords: Obesity, improvement, education

\section{PENDAHULUAN}

Menurut WHO (1998), obesitas adalah suatu keadaan terjadinya penimbunan jaringan lemak tubuh secara berlebihan. Penimbunan jaringan lemak inilah yang akan menimbulkan suatu penyakit. Obesitas berasal dari bahasa latin yaitu $o b$ yang artinya 'akibat dari' dan esum yang artinya 'makan'. Oleh karena itu, obesitas dapat didefinisikan sebagai akibat dari pola makan yang berlebihan (Adams et al., 2002; Syarif, 2003).

Obesitas termasuk dalam penyakit Non-Communicable Diseases (NCDs), atau biasa dikenal penyakit tidak menular, yang sangat perlu diperhatikan bagi masyarakat Indonesia. Obesitas menjadi salah satu masalah gizi yang perlu mendapatkan perhatian serius karena terjadi peningkatan prevalensi obesitas di seluruh dunia dalam satu dekade terakhir. Saat ini, masih banyak masyarakat yang menganggap bahwa obesitas hanya sekedar akibat yang ditimbulkan oleh seseorang yang menerapkan pola hidup tidak sehat selama perjalanan hidup seseorang, namun obesitas harus dianggap sebagai penyakit dan akan menimbulkan faktor risiko bagi penyakit serius lainnya, seperti diabetes, kanker, hipertensi primer, dan penyakit jantung. Penyakit-penyakit yang ditimbulkan dari 
obesitas ini bisa berakhir dengan kematian. Banyak penderita obesitas yang pada akhirnya meninggal.

Adanya hubungan antara obesitas dengan kardiovaskuler dilihat dari adanya peningkatan penumpukan plak, hiperaktivitas saraf simpatis, dan peningkatan kadar hormon insulin dalam darah. Pertama, penumpukan plak pada arteri menyebabkan arteri tersebut menyempit. Penyempitan arteri ini menyebabkan tekanan darah yang meningkat sehingga diperlukan tenaga yang lebih besar untuk memompa darah ke seluruh tubuh. Faktor kedua yang menyebabkan tekanan darah tersebut meningkat karena adanya hiperaktivitas saraf simpatis yang menyebabkan vasokonstriksi saraf simpatis. Untuk yang ketiga, adanya peningkatan kadar hormon insulin ini berkaitan dengan retensi natrium dan air yang mengakibatkan terjadinya peningkatan volume darah.

Obesitas yang dibahas di sini akan dibagi menjadi beberapa macam, yaitu berdasarkan lokasi penimbunan lemaknya, etiologi, dan patogenesisnya. Berdasarkan lokasi penimbunan lemaknya, obesitas dibagi menjadi dua, yaitu obesitas tipe pir dan obesitas tipe apel. Obesitas tipe pir ini memiliki ciri khas yaitu terdapat penimbunan lemak yang berlebih di daerah pinggul. Obesitas tipe pir sering dialami oleh wanita dibandingkan dengan pria. Obesitas tipe apel lebih banyak dialami oleh pria dan lebih berisiko mengalami penyakit serius lainnya, terutama penyakit kardiovaskuler. Hal ini dikarenakan lokasi perut lebih dekat ke jantung daripada perut ke pinggul.

Berdasarkan etiologinya, obesitas dibagi menjadi dua, yaitu obesitas primer dan obesitas sekunder. Obesitas primer dipengaruhi oleh makanan yang dimakan lebih banyak dibandingkan dengan kebutuhan energi yang sesuai dengan orang tersebut. Sedangkan obesitas sekunder dikarenakan terdapat penyakit yang nantinya akan berkaitan dengan obesitas, seperti kelainan sistem endokrin (cushing syndrome, freulich syndrome, mauriac syndrome, preudoparatiroidisme).

Berdasarkan patogenesisnya, obesitas juga dibagi menjadi dua, yaitu regulatory obesity dan metabolic obesity. Regulatory obesity terjadi akibat adanya gangguan di pusat pengatur masuknya makanan, yaitu di hipothalamus. Sedangkan metabolic obesity terjadi akibat adanya gangguan dalam proses mengolah energi, terutama pada metabolisme karbohidrat dan lemak.

Data yang dikeluarkan oleh organisasi kesehatan dunia atau World Health Organization (WHO) tahun 2016 menunjukkan bahwa obesitas merupakan masalah epidemiologi global yang menjadi ancaman serius bagi kesehatan masyarakat dunia. Data menunjukkan 41 juta anak dibawah umur 5 tahun, lebih dari 340 juta anak berumur 5-19 tahun, dan 1.9 miliar orang dewasa mengalami obesitas. Oleh karena itu, obesitas merupakan risiko penyebab kematian global, selain alkohol, tembakau, dan obat terlarang.

Tidak hanya di negara barat yang memiliki penghasilan yang tinggi, masalah obesitas juga meningkat secara signifikan di negara-negara berkembang, terutama di daerah perkotaan. Selama 20 tahun terakhir, obesitas meningkat secara signifikan di Indonesia. Terjadi peningkatan yang cukup 
drastis di kalangan wanita. Peningkatan penderita obesitas diiringi dengan perubahan gaya hidup dan pola makan di era sekarang yang dengan adanya perkembangan teknologi. Perkembangan teknologi ini memudahkan manusia dalam segala aktivitasnya sehingga dapat mengurangi aktivitas fisik seseorang.

Obesitas dapat didiagnosis melalui penilaian status gizi yang dilakukan dengan metode antropometri. Pengukuran antropometri sering digunakan dalam berbagai penelitian epidemiologi karena teknisnya yang cukup sederhana. Pengukuran antropometri ini terdiri dari pengukuran berat badan, tinggi badan, indeks massa tubuh (IMT), lingkar lengan atas (LILA), dan lingkar perut, lingkar pinggang dan panggul (PIPA). Dari pengukuran lingkar pinggang dan panggul inilah, bisa diketahui bentuk obesitas seseorang berdasarkan lokasi penimbunan lemaknya (tipe pir atau tipe apel).

Indikator obesitas IMT merupakan cara yang paling umum digunakan untuk memperkirakan obesitas. IMT ini sering digunakan karena memiliki beberapa keunggulan. Pertama, tindakannya sederhana. Kedua, mampu menggambarkan kelebihan berat badan. Ketiga, dapat digunakan dalam penelitian populasi skala sederhana. Untuk pengukurannya, dengan melakukan pembagian antara berat badan $(\mathrm{kg})$ dengan kuadrat tinggi badan $\left(\mathrm{m}^{2}\right)$. Berikut tabel interpretasi hasil IMT berdasarkan Departemen Kesehatan RI.

\begin{tabular}{|c|c|c|}
\hline & Kategori & IMT \\
\hline \multirow{2}{*}{ Kurus } & Kekurangan berat badan tingkat berat & $<17,0$ \\
\cline { 2 - 3 } & Kekurangan berat badan tingkat ringan & $17,0-18,4$ \\
\hline Normal & & $18,5-25,0$ \\
\hline Gemuk & Kelebihan berat badan tingkat ringan & $25,1-27,0$ \\
\cline { 2 - 3 } & Kelebihan berat badan tingkat berat & $>27,0$ \\
\hline
\end{tabular}

Tindakan preventif yang harus dilakukan sejak dini untuk mencegah obesitas adalah bisa dengen mengatur pola makan yang lebih sehat dengan memperbanyak sayur hijau dan buah-buahan, memperbanyak aktivitas fisik dan olahraga, mengurangi makanan dan minuman manis, serta memodifikasi pola hidup yang tidak sehat seperti dengan mengontrol keinginan untuk makan.

\section{METODE}

Sebuah penelitian harus disusun dengan cara yang tepat, tidak bisa seenaknya dalam menggunakan metode penelitian. Penggunaan metode itu disesuaikan dengan tujuan diadakannya penelitian itu sendiri dan permasalahan yang akan diteliti pada suatu objek. Penelitian kualitatif adalah penelitian yang dilakukan pada kondisi objek yang alami, peneliti sebagai instrumen kunci, teknik pengumpulan data dilakukan secara gabungan, data yang dihasilkan bersifat deskriptif, analisis 
data dilakukan secara induktif, dan penelitian ini lebih menekankan makna daripada generalisasi (Sedarmayanti dan Hidayat, 2011: 33).

Metode yang digunakan penulis dalam penelitian ini adalah metode kualitatif. Metode kualitatif ini dilakukan melalui dua cara, yaitu pengamatan saat dilakukan edukasi dan intervensi kepada masyarakatnya, serta melakukan wawancara kepada mahasiswa yang terlibat dalam project GANBATTE CIMSA FK UNS.

\section{HASIL DAN PEMBAHASAN}

Hasil wawancara terhadap enam orang responden yang terlibat dalam project GANBATTE CIMSA FK UNS ini relatif sama. Pertanyaan yang diajukan dalam wawancara ini, yaitu:

1. Apakah yang dimaksud dengan obesitas?

2. Bagaimanakah kesadaran masyarakat daerah Gulon terkait obesitas?

3. Bagaimana metode yang diterapkan dalam mengedukasi obesitas kepada masyarakat daerah Gulon?

4. Bagaimana hasil edukasi obesitas yang telah dilakukan?Apakah mengalami penurunan selama intervensi tersebut?

5. Apa faktor pendukung dan penghambat dalam mengedukasi masyarakat daerah Gulon?

Pemahaman responden terkait obesitas sudah cukup baik. Mereka memahami obesitas secara garis besar. Obesitas ini merupakan masalah kesehatan yang dibahas dalam project GANBATTE CIMSA FK UNS. Obesitas merupakan masalah kesehatan dikarenakan adanya penumpukan jaringan lemak pada tubuh seseorang. Seseorang dikatakan obesitas ketika IMT nya di atas $23.5 \mathrm{~kg} / \mathrm{m}^{2}$.

Untuk kesadaran dari masyarakat daerah Gulon sendiri terkait obesitas itu sudah cukup baik. Dikatakan cukup baik karena pengetahuan mereka tentang obesitas sudah bagus, dilihat dari hasil pretest dan posttest yang diberikan kepada masyarakat daerah Gulon. Namun, dalam mengimplementasikan ilmu tersebut dalam kehidupan sehari-hari mereka masih sangat kurang. Mereka masih kurang dalam melakukan tindakan preventif terhadap obesitas. Hal ini dikarenakan pola hidup mereka yang sudah diterapkan dalam jangka waktu yang cukup lama sulit untuk diubah dan kesadaran masyarakat terhadap bahaya dari komplikasi obesitas tersebut masih sangat kurang.

Metode yang diterapkan oleh project GANBATTE CIMSA FK UNS ini dalam melakukan edukasi terkait obesitas kepada masyarakat dilakukan secara rutin dan dalam jangka waktu yang cukup lama. Dilakukan metode follow up kepada masyarakat yang diedukasi melalui kegiatan family 
time. Kegiatan family time ini dilakukan secara rutin minimal 2 minggu sekali, sesuai kesepakatan antara mahasiswa dengan masyarakat yang diedukasi.

Untuk hasil edukasi obesitas ini sudah cukup baik karena adanya peningkatan pengetahuan masyarakat terkait obesitas melalui hasil pretest dan posttestnya. Namun, peningkatan pengetahuan yang ada tidak sejalan dengan penurunan IMTnya. Jadi, terjadi peningkatan dalam pengetahuan obesitas dan tidak ada perubahan dalam implementasi tindakan preventifnya pada masyarakat daerah Gulon.

Faktor pendukung dalam menjalankan project GANBATTE CIMSA FK UNS ini yaitu masyarakat yang kooperatif dan semangat serta keikhlasan dari mahasiswa yang terlibat dalam project ini untuk mengedukasi masyarakat secara langsung sehingga intervensi yang sudah dilakukan dapat berjalan lancar. Sedangkan, faktor penghambatnya adalah waktu yang sesuai untuk melakukan family time dan padatnya jadwal kuliah dari mahasiswanya.

\section{SIMPULAN}

Setelah dilakukan pendekatan analisis isi dapat disimpulkan bahwa obesitas merupakan suatu masalah gizi yang perlu diperhatikan karena akan berlanjut ke penyakit serius yang bisa menimbulkan kematian. Pemahaman masyarakat tentang obesitas sudah cukup baik, namun untuk pemahaman dalam bahaya obesitasnya masih kurang sehingga masyarakat masih kurang sadar dan penerapan dalam kehidupan sehari-harinya yang cukup sulit. Adanya project GANBATTE CIMSA FK UNS ini meningkatkan pemahaman dan kesadaran masyarakat terkait bahaya obesitas.

\section{SARAN}

Sejauh ini, masyarakat sudah paham secara teori mengenai obesitas. Namun, karena penerapan dalam mencegah obesitas di kehidupan sehari-hari yang masih kurang, sebaiknya perlu dioptimalisasi lagi intervensi dalam melakukan edukasi terkait obesitas kepada masyarakat daerah Gulon. Kesadaran masyarakat terhadap bahaya obesitas perlu ditingkatkan lagi sehingga masyarakat secara perlahan bisa mengubah pola hidup mereka menjadi lebih sehat.

\section{DAFTAR PUSTAKA}

\section{Buku}

1. Freitag, Harry, Felicia Rosiyani, Nur Aini Kusmayanti, dan Toto Sudargo. (2014). Pola Makan dan Obesitas. Yogyakarta : Gadjah Mada University Press.

2. Sherwood, L. (2017). Fisiologi Manusia: dari Sel ke Sistem Edisi 8. Jakarta : EGC.

3. Silverthorn, D. U. (2014). Fisiologi Manusia (Sebuah Pendekatan Terintegrasi) (Vol. Edisi 6). Jakarta: Penerbit Buku Kedokteran : EGC.

Jurnal

1. Edward, Aspinall. (2014). Health care and democratization in Indonesia, Democratization, 21:5, 803-823, DOI: 10.1080/13510347.2013.873791 
2. Roemling, Cornelia dan Matin Qaim. (2012). Obesity Trends and Determinants in Indonesia Vol 58 (3). Journal of Appetite.

3. Depkes RI. Hasil Utama Riskesdas 2018. Jakarta : Badan Penelitian dan Pengembangan Kesehatan Depkes RI; 2018.

4. World Health Organization. (2018). Obesity and Overweight. 2018 [cited 201920 July]. Available from: www.who.int.

5. Kemenkes RI. 2016. Menkes: Sebagian Kasus Diabetes Sebenarnya Bisa Dicegah. Jakarta: Kemenkes RI

6. SCOPH CIMSA. 2018. Panduan Mengatasi Obesitas. CIMSA Indonesia

\section{LAMPIRAN}

\section{Narasumber 1}

Peneliti : Apakah yang dimaksud dengan obesitas?

Responden : Obesitas kalau imt nya lebih dari $23.5 \mathrm{~kg} / \mathrm{m}^{2}$.

Peneliti $\quad$ : Bagaimanakah kesadaran masyarakat daerah Gulon terkait obesitas?

Responden : Sebenernya buat edukasi sudah baik (olahraga berapa kali seminggu, gaboleh makan diatas jam 10, kurangin konsumsi lemak dl1). Namun untuk implementasi dalam kehidupan sehari hari masih sangat kurang, bisa aja karena males atau karena emg blm aware sama obesitas padahal obesitas itu bisa menyebabkan banyak penyakit.

Peneliti : Bagaimana metode yang diterapkan dalam mengedukasi obesitas kepada masyarakat daerah Gulon?

Responden $\quad$ : Menurut aku harus sustainaible sih, gabisa cuma sekali dua kali jadi bener bener harus diingetin terus menerus (menggunakan metode follow up ganbatte yang family time).

Peneliti : Bagaimana hasil edukasi obesitas yang telah dilakukan?Apakah mengalami penurunan selama intervensi tersebut?

Responden $\quad$ : Hasil edukasi sebenernya udah bagus dilihat dari peningkatan pretest dan postest (quiz) yang dilakukan saat famtime, namun peningkatan pengetahuan ini tidak sejalan dengan penurunan IMT. Mungkin bisa juga karena IMT buat nuruninnya kan tidak semudah itu. Jadi, butuh waktu juga.

Peneliti : Apa faktor pendukung dan penghambat dalam mengedukasi masyarakat daerah Gulon? 
Responden $\quad$ Faktor pendukungnya adalah masyarakat yang kooperatif dan member CIMSA yang memiliki niat yang tulus buat edukasi langsung ke masyarakat. Sedangkan faktor penghambatnya yaitu jadwal akademis.

\section{Narasumber 2}

Peneliti : Apakah yang dimaksud dengan obesitas?

Responden : Suatu kondisi medis berupa kelebihan lemak tubuh yang terakumulasi sedemikian rupa sehingga menimbulkan dampak merugikan bagi kesehatan, yang kemudian menurunkan harapan hidup dan/atau meningkatkan masalah kesehatan (menkes, 2003).

Peneliti $\quad$ : Bagaimanakah kesadaran masyarakat daerah Gulon terkait obesitas?

Responden $\quad$ : Setelah dilakukan assessment didapatkan bahwa pengetahuan masyarakat Gulon terkait obesitas sudah baik, namun banyak dari warga masih tidak sadar akan bahaya obesitas serta tidak menerapkan pola hidup sehat.

Peneliti : Bagaimana metode yang diterapkan dalam mengedukasi obesitas kepada masyarakat daerah Gulon?

Responden : Ada dua metode yang digunakan, yang pertama adalah metode "famtime" yaitu dengan melakukan kunjungan ke rumah-rumah warga dengan tujuan melakukan penyuluhan terkait bahaya obesitas dan pola hidup sehat. Metode yang kedua yaitu dengan melakukan senam rutin tiap minggu keempat di tiap bulannya yang bertujuan agar warga Gulon bisa melakukan aktivitas fisik secara rutin tiap bulannya.

Peneliti : Bagaimana hasil edukasi obesitas yang telah dilakukan?Apakah mengalami penurunan selama intervensi tersebut?

Responden : Dari hasil edukasi yang telah dilakukan beberapa kali, serta melalui pretest dan postest yang dilakukan, didapatkan peningkatan pengetahuan dari warga gulon terkait obesitas dan pola hidup sehat.

Peneliti : Apa faktor pendukung dan penghambat dalam mengedukasi masyarakat daerah Gulon?

Responden $\quad$ :Faktor pendukung dalam mengedukasi masyarakat gulon yaitu, daerah yang dekat dengan kampus, warga yang cukup mudah diajak berkomunikasi serta semangat dari member hingga membuat semuanya berjalan lancar. Faktor yang menghambat adalah tidak semua warga memiliki waktu luang untuk dilakukan famtime dan padatnya jadwal kuliah. 


\section{Narasumber 3}

Peneliti : Apakah yang dimaksud dengan obesitas?

Responden : Penumpukan jaringan lemak dalam tubuh.

Peneliti : Bagaimanakah kesadaran masyarakat daerah Gulon terkait obesitas?

Responden : Kesadaran masyarakat Gulon terkait obesitas memang tidak tinggi, terbukti dengan banyaknya warga yang masih mengalami obesitas baik pre-obesitas ataupun obesitas.

Peneliti : Bagaimana metode yang diterapkan dalam mengedukasi obesitas kepada masyarakat daerah Gulon?

Responden : Metode yang GANBATTE CIMSA FK UNS terapkan adalah dengan mengadakan senam kesehatan setiap minggu ke empat setiap bulan dan melakukan famtime ke rumah warga yang mengalami obesitas untuk melakukan edukasi dan mengecek berat badan dan lingkar panggul pinggul.

Peneliti $\quad$ : Bagaimana hasil edukasi obesitas yang telah dilakukan?Apakah mengalami penurunan selama intervensi tersebut?

Responden $\quad$ : Hasil edukasi yang diterapkan menurut saya cukup berhasil, dilihat dari nilai post test yg lebih tinggi dari nilai pretest.

Peneliti : Apa faktor pendukung dan penghambat dalam mengedukasi masyarakat daerah Gulon?

Responden : Hambatan dari famtime GANBATTE CIMSA FK UNS sendiri adalah kesulitan dalam menentukan waktu yang tepat untuk melakukan famtime karena sebagai mahasiswa FK sendiri kami cukup sibuk, akan tetapi antusiasme warga lumayan baik.

\section{Narasumber 4}

Peneliti : Apakah yang dimaksud dengan obesitas?

Responden : Jumlah lemak di tubuh di luar batas normal (berat badan berlebih) sehingga bisa mengganggu kesehatan tubuh kita. 
Peneliti $\quad$ : Bagaimanakah kesadaran masyarakat daerah Gulon terkait obesitas?

Responden $\quad$ : Kesadaran masyarakat Gulon terkait obesitas masih kurang paham, maka dari itu project GANBATTE CIMSA FK UNS menjadikan hal ini sebagai target dalam melakukan aksinya.

Peneliti : Bagaimana metode yang diterapkan dalam mengedukasi obesitas kepada masyarakat daerah Gulon?

Responden : Family time. Jadi, kita melakukan intervensi ke rumah warga yang sudah dijadikan sebagai target kegiatan, edukasinya melalui ketemu langsung, kita kayak memberikan pretest dulu ke warganya biar kita tau sejauh mana ibu/bapak nya paham mengenai tingkat kesadaran bahaya obesitas. Kalau udah nanti kita jelasin \& ada buku panduannya juga trus setelah itu ada postest lagi buat memastikan kalau ibu/bapak/dsb paham penjelasan kita.

Peneliti $\quad$ : Bagaimana hasil edukasi obesitas yang telah dilakukan?Apakah mengalami penurunan selama intervensi tersebut?

Responden : Sejauh yang aku tauu mungkin ada yang turun ada yang engga juga, aku cuma tau dari temen kalau keluarga yang menjadi target dia malah naik lingkar pinggang/pinggul nya.

Peneliti : Apa faktor pendukung dan penghambat dalam mengedukasi masyarakat daerah Gulon?

Responden : Faktor pendukungnya alhamdulillah kita anak kesehatan juga jadi lumayan paham sama apa yang kita sampaikan dan tidak memberikan penjelasan secara sembaranagang dan ada buku panduannya di cross check juga jadi ga asal, lokasi dekat, alat-alat kesehatan yang kita punya juga memadai lah buat cek-cek kesehatan warganya dll. Untuk faktor penghambatnya waktunya kurang dan sedikit, jadwal kuliah yang padat, dan famtime kurang rutin.

\section{Narasumber 5}

Peneliti : Apakah yang dimaksud dengan obesitas?

Responden $\quad$ Kelebihan berat badan yang tidak sesuai indeks massa tubuhnya.

Peneliti $\quad$ : Bagaimanakah kesadaran masyarakat daerah Gulon terkait obesitas?

Responden $\quad$ : Kurang sadarr siii baru kerasa pas udah terkena obesitas.

Peneliti : Bagaimana metode yang diterapkan dalam mengedukasi obesitas kepada masyarakat daerah Gulon? 
Responden : Pendekatan sama masyarakatnya dan dijelaskan terkait kemungkinan apa saja penyakit yang timbul akibat obesitas.

Peneliti $\quad$ : Bagaimana hasil edukasi obesitas yang telah dilakukan?Apakah mengalami penurunan selama intervensi tersebut?

Responden : Kalau target aku sih mengalami penurunan karena ibunya mendengarkan apa yang kita sampaikan, seperti mengurangi makan berminyak, manis, dan sebagainya.

Peneliti : Apa faktor pendukung dan penghambat dalam mengedukasi masyarakat daerah Gulon?

Responden : Pendukungnya itu kerjasama dari si ibu tersebut. Penghambatnya minimnya intervensi jadi kita terlalu jarang ngecek dan edukasi, serta gaada buku yang memberikan informasi si ibu makan apa aja jadi sulit dikontrol oleh kita.

\section{Narasumber 6}

Peneliti : Apakah yang dimaksud dengan obesitas?

Responden : Kegemukan yang terjadi akibat kurangnya aktivitas fisik dan pola hidup yang tidak sehat.

Peneliti : Bagaimanakah kesadaran masyarakat daerah Gulon terkait obesitas?

Responden : Menurut saya, masyarakat daerah Gulon secara teori sudah mengetahui tentang obesitas ini, namun dalam penerapannya untuk mencegah obesitas masih sangat kurang.

Peneliti : Bagaimana metode yang diterapkan dalam mengedukasi obesitas kepada masyarakat daerah Gulon?

Responden : Metode yang dilakukan melalui edukasi. Edukasi ini sudah cukup baik, namun dikarenakan kendalanya adalah penerapan secara langsung, ya jadi sulit bagi mereka untuk berubah.

Peneliti : Bagaimana hasil edukasi obesitas yang telah dilakukan?Apakah mengalami penurunan selama intervensi tersebut?

Responden : Hasilnya ada, target yang aku intervensi minum tehnya udah berkurang. Tidak ada penurunan maupun peningkatan yang signifikan terhadap pencegahan obesitas ini.

Peneliti : Apa faktor pendukung dan penghambat dalam mengedukasi masyarakat daerah Gulon? 
Responden : Faktor pendukungnya adalah antusiasme dari warga daerah Gulon yang mau diintervensi dan rutin mengikuti kegiatan senam yang diadakan, sedangkan faktor penghambatnya adalah lifestyle yang sulit untuk diubah. 